\title{
Brief Introduction to a Unique Edible Bolete-Phlebopus portentosus in Southern China
}

\author{
Chunxia Zhang ${ }^{1}$, Mingxia $\mathrm{He}^{1}$, Jing $\mathrm{Liu}^{1}$, Xinjing $\mathrm{Xu}^{1}$, Yang $\mathrm{Cao}^{1}$, Feng $\mathrm{Gao}^{1}$, Yiwei Fang ${ }^{1}$, Wenbing Wang ${ }^{1}$ and \\ Yun Wang ${ }^{2}$ \\ 1. Yunnan Institute for Tropical Crop Research, 99 Xuanwei Rd., Jinghong 666100, Yunnan, China \\ 2. The New Zealand Institute for Plant \& Food Research Ltd., Private Bag 4704, Christchurch 8140, New Zealand
}

\begin{abstract}
Phlebopus portentosus (Berk. and Broome) Boedijn is a favored wild edible mushroom in the Xishuangbanna region, Yunnan, China and Northern Thailand. It belongs to Boletinellaceae family and is known as "black bolete". Its ecological habits and biotrophy are very complicated. It can be saprobic and successfully cultivated in mushroom house conditions. More often it grows closely with many plants, but is not mycorrhizal fungus. It forms a tripartite association with root mealy bugs and plants. The fungus produces special fungus-insect gall with the soil mealy bugs, which is a symbiotic association between these two creatures. The gall grows on plant roots with parasitic tendency. This paper is a compact report of the findings, including taxonomy, ecology, economic and cultivation of this mushroom.
\end{abstract}

Key words: Phlebopus portentosus, ecology, cultivation, fungus-insect gall, biotrophy, economy, China.

\section{Introduction}

Phlebopus portentosus (Berk. and Broome) Boedijn is a good wild edible mushroom in the Xishuangbanna region, Yunnan, China and Northern Thailand (Figs. 1 and 2). In particular, it is a favorite of the Dai people, and is known as "Hei-ben-ma-lang" [1, 2]. It is also found in other tropical and warm subtropical regions of China, and is known as "black bolete" in Yunnan's wild mushroom markets due to its dark-brown fruiting body [3, 4]. This fungus was initially described as Boletus portentosus Berk. \& Broome from Sri Lanka $[5,6]$. It is a member of the Boletinellaceae family now $[7,8]$.

$P$. portentosus is delectable and rich in nutrients, including proteins, amino acids and minerals, and thus is a very popular delicacy in the Xishuangbanna region, Yunnan [2,9]. It sells for US $\$ 10-15 / \mathrm{kg}$ at local farmers' markets, a higher price than that of most other wild edible mushroom species. Collection and trade of $P$. portentosus can thus bring good

Corresponding author: Yun Wang, Ph.D., research fields: ecology, taxonomy and cultivation of edible fungi. incomes to the local farmers. It is an important means of livelihood for the local people (Fig. 3). Resource shortage and market demand have led to this research into cultivation of the mushroom at the Yunnan Institution for Tropical Crop Research. Greenhouse cultivation technology based on its saprobic biotrophy has been developed. The new methods of cultivation of $P$. portentosus have also been developed, according to the relationship between fungus, mealy bugs and plants, for example, with orchard trees, generating potential secondary income for orchards [9-11].

During this research, the unique ecological habits and biotrophy of $P$. portentosus have been gradually unveiled. This mushroom can live a saprophytic lifestyle [10-14]. However, it usually has a symbiotic association with soil mealy bugs, forming a special insect gall on plant roots. It is called "fungus-insect gall", because the insect gall differs from common insect galls in that the crusty wall is made by the hyphae of $P$. portentosus rather than from the plant tissues [4]. In this unique tripartite lifestyle, the fungus-insect galls can have parasitic effects on plants, and more researches are needed for a thorough 


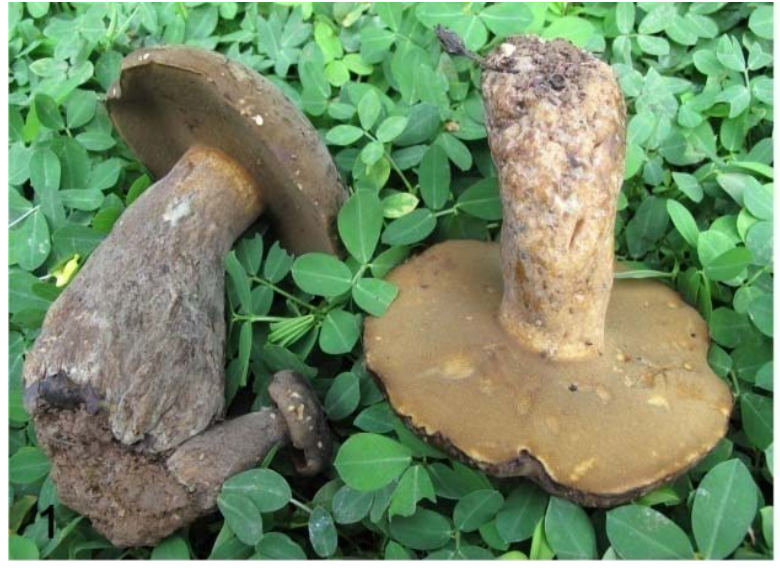

Fig. 1 Fruiting bodies of $P$. portentosus.

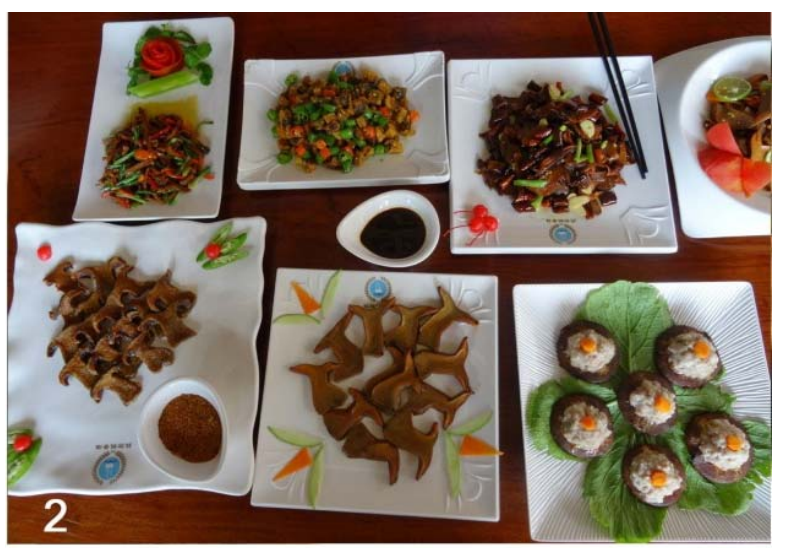

Fig. 2 Dishes made from $P$. portentosus.

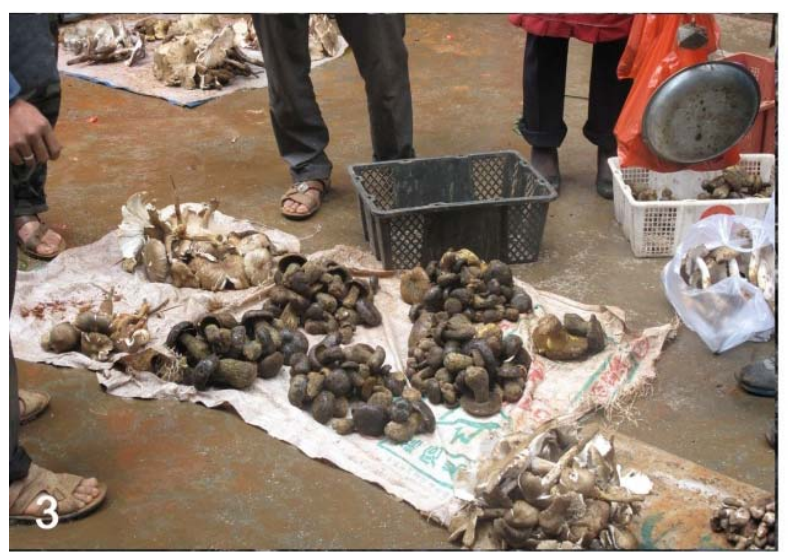

Fig. 3 P. portentosus sold at a local farmers' market, Gejiu, Yunnan.

understanding. This paper provides the research findings with a focus on taxonomy, ecology, economic and cultivation of this mushroom.

\section{Taxonomy and Distribution in China}

In China, although this edible black bolete, as a delicacy, has been well-known for a long time, however, its taxonomic position has been uncertain until recently. The first record of the fungus was Boletus brevitubus, which was described as a new species by Zang [15] based on a collection from Nanshahe, Yuanyang county, Yunnan (HKAS 516). However, Lei et al. [16] mentioned that this species is conspecific with $P$. portentosus due to having broad-ellipsoid spores and clamp connections. In the "Flora Fungorum Sinicorum: Boletaceae (I)", Zang recorded another species, Boletus dimocarpicola [15]. This fungus was originally reported as a new species in Fungal Science in 1999 based on a type collection from Chiang Mai, Thailand (HKAS 32706). This species, however, also has broad-ellipsoid spores and clamp connections and is likely to be conspecific with $P$. portentosus. In the same monograph, Zang did record the species B. portentosus (= P. portentosus) based on collections from Nanning, Guangxi (HKAS 23441 and 23439) and Hainan (Gong MQ 9014), China. However, re-examination of these specimens has found that these have fucoid spores and no clamp connections, and thus differ greatly in morphology from Phlebopus, and more closely resemble Boletus species. In 2009, Lei et al. reported [16] the occurrence of P. marginatus Watling \& N. M. Greg in the Xishuangbanna, Yunnan, based on their collections from Xishuangbanna, and indicated that $P$. portentosus and B. brevitubus were synonymous with P. marginatus. P. marginatus was published based on collections from the vicinity of the Swan River Colony in Western Australia [5], which differs from $P$. portentosus in having no diverse cystidia on the hymenium and is also clearly separated in molecular analysis [4]. P. portentosus (Berk. \& Broome) Boedijn is the most appropriate name for the Chinese edible black bolete based on the authors' research results. However, because no molecular data are available from the type collection of $P$. portentosus, this conclusion cannot be absolutely sure even though no morphological differences between the 
Chinese specimens of black bolete and the Sri Lankan type collection of $P$. portentosus [6]. P. portentosus has now been found in Southern China, Northern Thailand, Laos and Myanmar [13, 17, 18]. Previous reports suggested that $P$. portentosus occurred in New Zealand and Australia [19], but this is incorrect $[4,11]$. The identification features of Phlebopus species are broad-ellipsoid spores and hyphae with clamp connections. Phlebopus is one of two genera in the Boletinellaceae $[7,8]$. The name Boletus brunneissimus Chiu was misused for $P$. portentosus in the previous publication of the authors [20].

P. portentosus has been found at more than 20 locations in China, between $18^{\circ} 41^{\prime} \mathrm{N}$ and $26^{\circ} 55^{\prime} \mathrm{N}$, in the tropical regions of Yunnan province, Hainan province, and the warm subtropical regions of Sichuan, Yunnan province and the Guangxi region (Fig. 4).

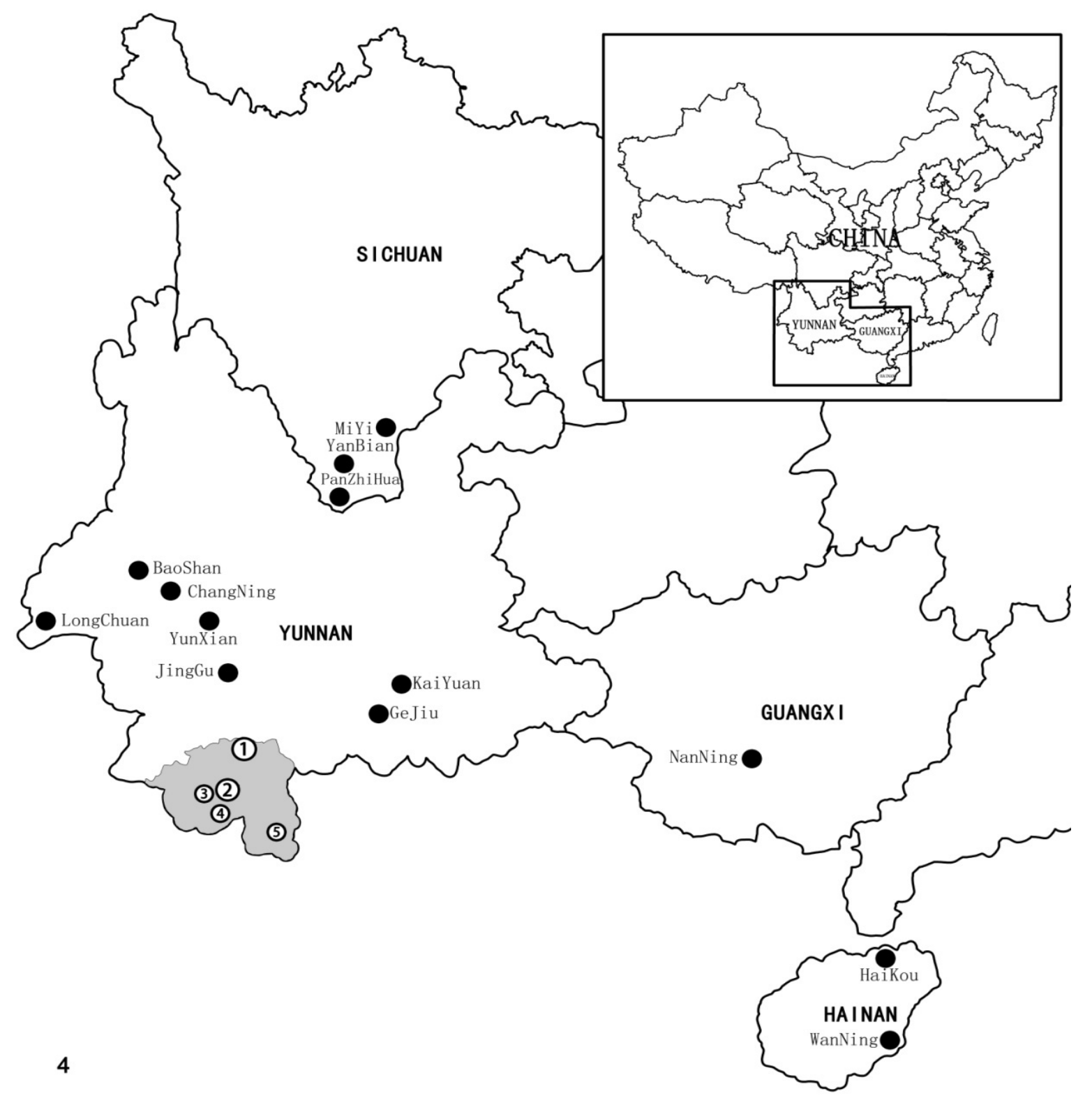

Fig. 4 Map of locations where $P$. portentosus is found.

(1) Nandaohe, Nanping, Puwen; (2) Jinghong, Mengyang, Xishuangbanna tropical flowers and plants garden; (3) Menghai; (4) Damenglong; (5) Mengla. 
Closely related species have been reported from Vietnam, Indonesia, Brazil, Mexico, Australia, New Zealand and other tropical regions [19, 21-26], but their taxonomic identities need further study.

\section{Ecology and Biology}

$P$. portentosus originates from natural ecosystems, such as tropical seasonal rain forests with brown latosol (below 800 masl) and subtropical evergreen broad-leaf forests with yellow lateritic soil (900-1,800 masl), between $21^{\circ} 01^{\prime} \mathrm{N}$ and $24^{\circ} 40^{\prime} \mathrm{N}$ (Figs. 5 and 6). In recent years, however, this mushroom has been found mainly in artificial ecosystems, such as orchards (Fig. 7), parks, campuses and nurseries [27]. $P$. portentosus is more productive in these artificial ecosystems than in the natural ones. This is probably because the artificial ecosystems have fertile soils and are more open to sunlight. It can adapt to a big range soils from the poor red soil to rich farmland soils with $\mathrm{pH}$ of 4.5-6.5. However, it is addicted to richer and looser soils with high $\mathrm{N}$ content. Application of compost to $P$. portentosus sites can stimulate and increase production of the mushroom. The temperature is the limiting factor to its growth and distribution. It can only grow at regions south to $26^{\circ} 55^{\prime} \mathrm{N}$, with the annual average temperature above $19.7{ }^{\circ} \mathrm{C}$, the annual minimum temperature of $-2.4{ }^{\circ} \mathrm{C}$ and the annual accumulated temperature $7,208.2{ }^{\circ} \mathrm{C}$ (above $0{ }^{\circ} \mathrm{C}$ ). Rainfall stimulates formation of fruiting bodies of the mushroom; the more rainfall, the more mushrooms produced. It is very sensitive to the application of the farm chemicals, especially herbicides. Application of herbicides will severely inhibit the fungal mycelia growth, even completely kill them. This effect can last for many years.

\section{Saprophytic Life}

In natural environments, $P$. portentosus can be found at bare lands without any plants nearby, even though this is rare. This means that this mushroom can live a saprophytic life style. Its saprophytic habit has been further confirmed by successful cultivation of the mushroom using saprophytic methods (Fig. 8) [10-12].

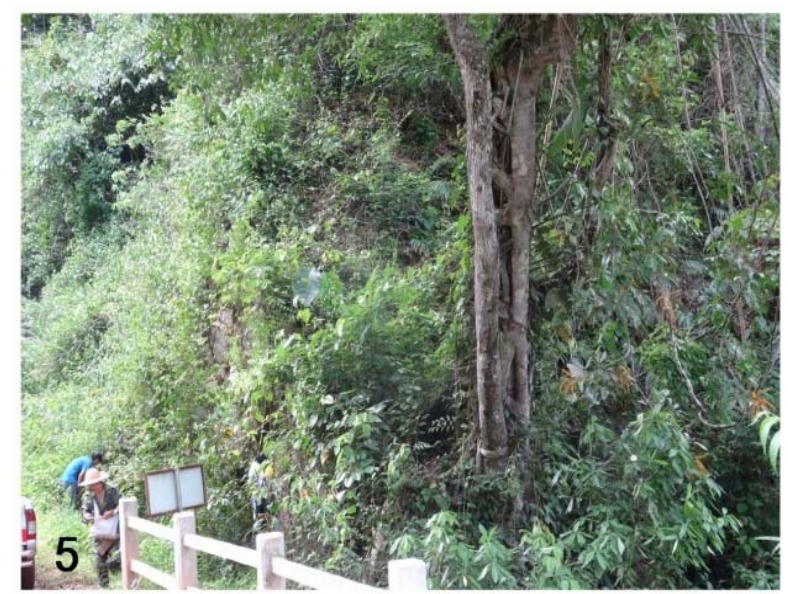

Fig. 5 A $P$. portentosus natural habitat of a tropical forest with a big Ficus tree.

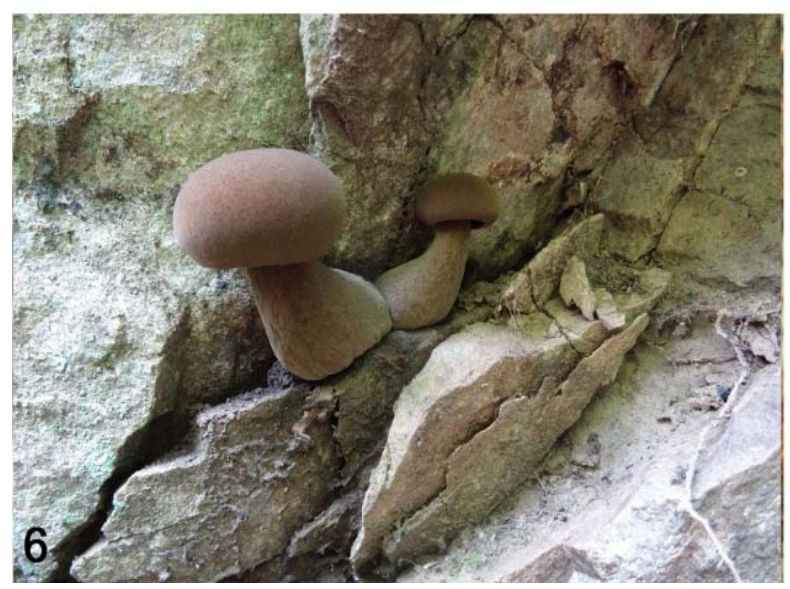

Fig. 6 Mushrooms of $P$. portentosus growing around the Ficus tree.

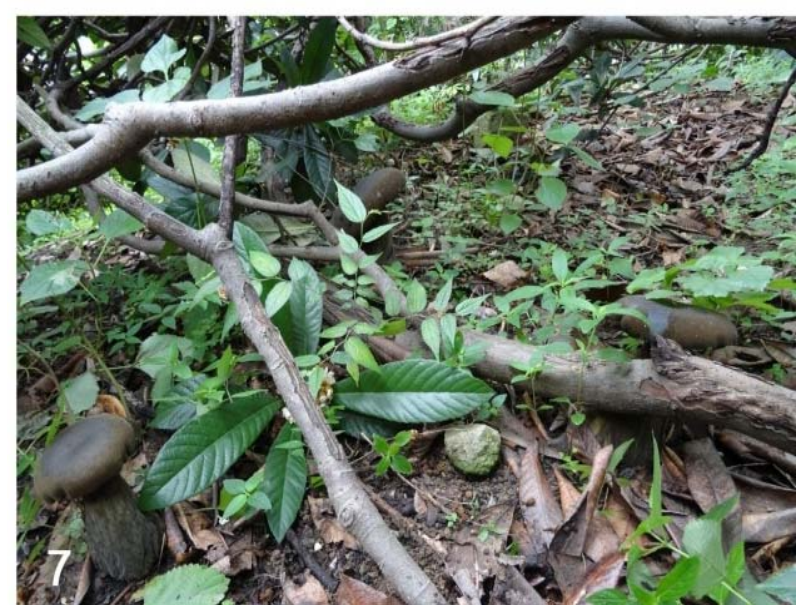

Fig. 7 Fruiting bodies of $P$. portentosus around Eriobotrya japonica trees. 


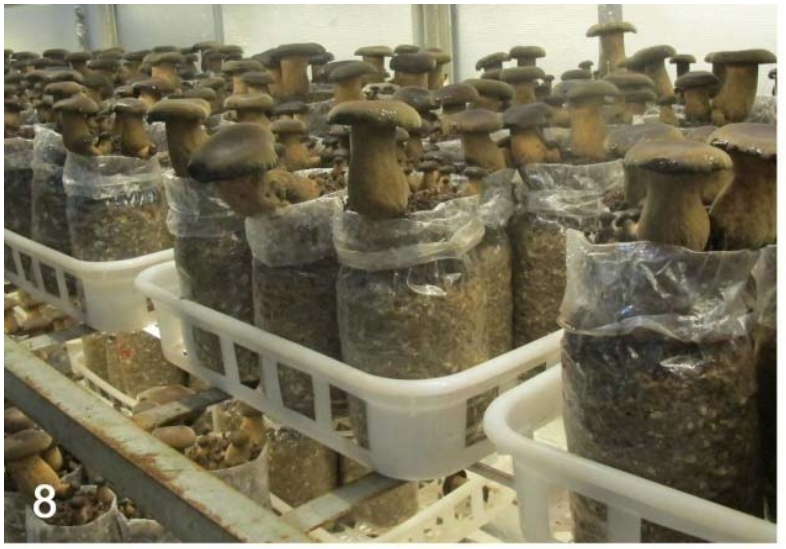

Fig. 8 P. portentosus cultivated in a mushroom house, Jinghong, Yunnan.

\section{Non-mycorrhizal Fungus}

However, the fruiting bodies of the mushroom normally grow around natural or planted plants (trees, shrubs and herbal plants), such as Delonix regia, Coffea arabica, Citrus grandis, Wedelia trilobata, Arachis duranensis and Syzygium cumini. Therefore, at the early stage of the research, it was expected that $P$. portentosus could be mycorrhizal as Sanmee et al. reported [28] that $P$. portentosus was a facultative ectomycorrhizal fungus. However, the expectation was finally rejected by the results of further research, which included the field investigations and a series tests of mycorrhizal pure culture synthesis. These results revealed that there were no any mycorrhizal structures formed, although the mycelium of $P$. portentosus grew densely on the roots of some trees [28]. Then, $P$. portentosus is not ectomycorrhizal fungus.

\section{Tripartite Association}

And then, its ecological and biotraphic habits can be more complicated as in the later research. The unique insect galls were discovered when doing examination of ecological relationship between the $P$. portentosus and plant roots. The galls were often found on plant root system, which the mushrooms formed with root mealy bugs, and these are different from common insect galls in that their cavity walls (crusts) are made from the hyphae of $P$. portentosus rather than from plant tissue. It was named as "fungus-insect gall" (Figs. 9-11). Over the past 10 years, more than 13 root mealy bug species in three families of Pseudococcidae, Eriococcidae and Monophlebidae have been found to form these galls with $P$. portentosus. The fungus-insect gall has been found on roots of more than 20 plant species. The research shows that $P$. portentosus has a symbiotic lifestyle with mealy bugs through forming the fungus-insect gall and that parasitizes plant roots [4]. The galls constituted by $P$. portentosus mycelia provide wonderful habitations for the mealy bugs and the mealy bugs produce honey dew for the fungus (Fig. 12). Based on the results of analyses of the honey dew, it contains rich sucrose and 17 amino acids, which provide extra nutrients to the fungus. The tests indicated that the honey dew can stimulate mycelia growth and form the insect-fungus galls. In the field, the production of the mushrooms is positively related to

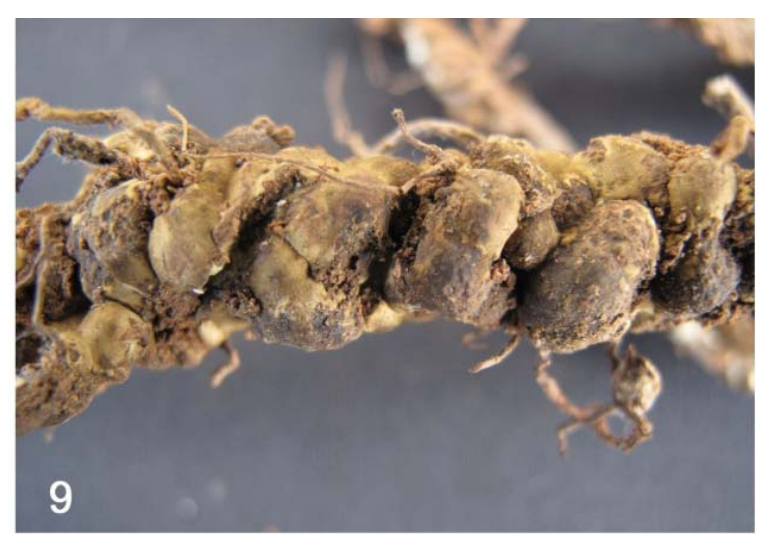

Fig. 9 A bead-like insect-fungus galls on a $D$. regia root.

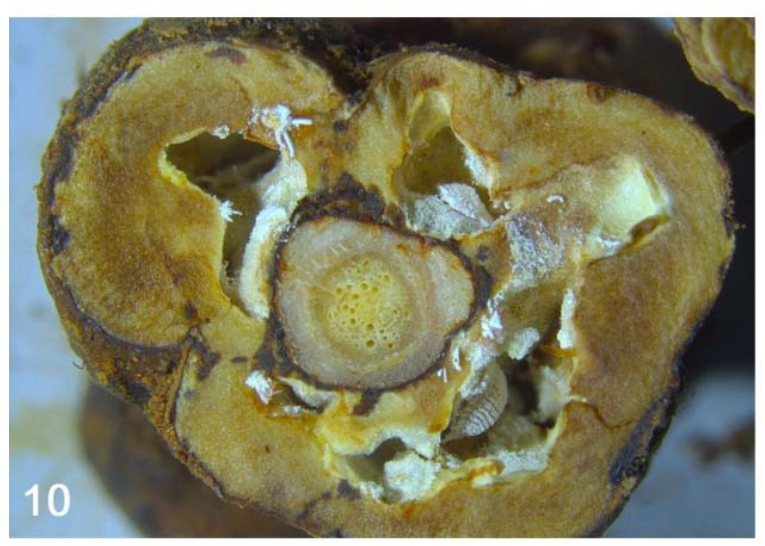

Fig. 10 A cross-section of an insect-fungus gall on a $D$. regia root. 


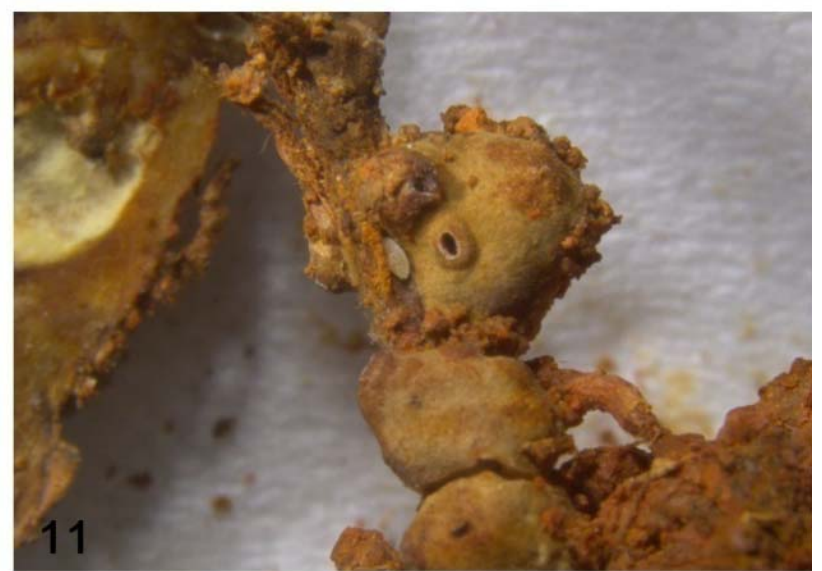

Fig. 11 An insect-fungus gall with chimney-like holes.

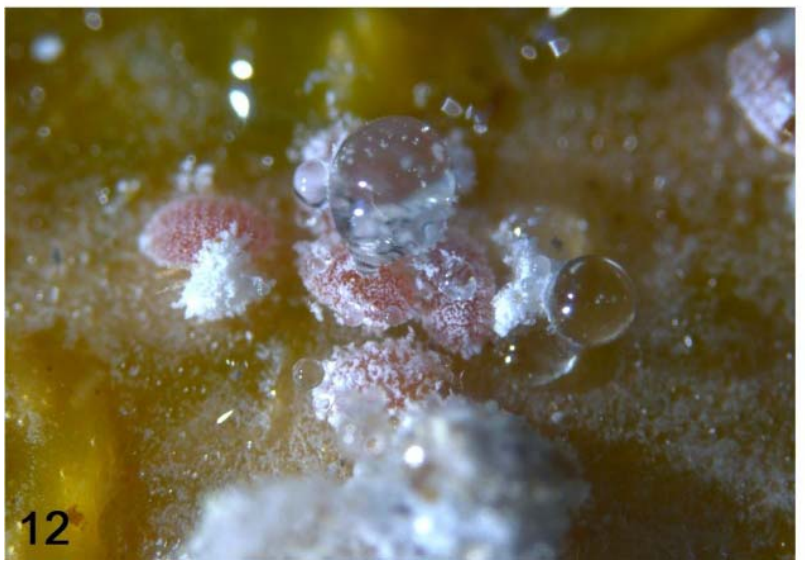

Fig. 12 Mealy bugs produced honey dew.

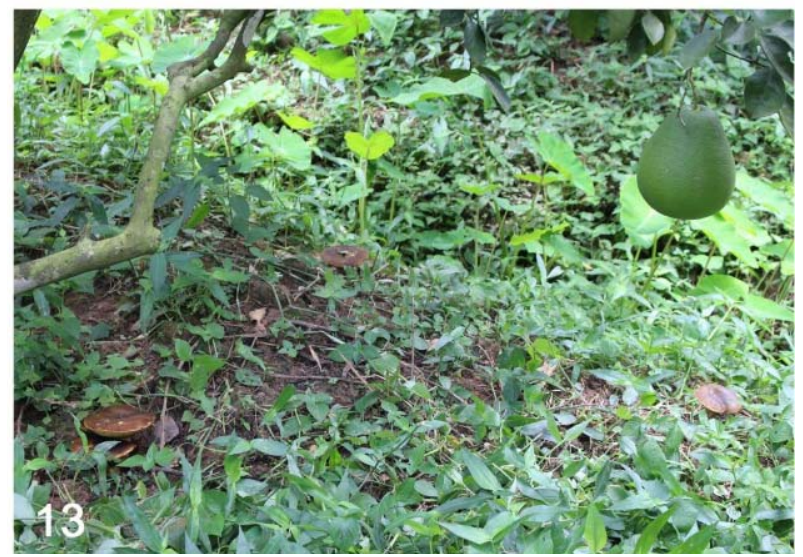

Fig. 13 Cultivation of $P$. portentosus by the field inoculation of $C$. grandis trees at the Dongfeng orchard, Jinghong, Yunnan.

formation of the insect galls on the plant roots. The fungus-insect galls can have parasitic effects on plants. The plants could be killed when the galls densely developed on the whole root system (unpublished data).

\section{Economic Importance}

P. portentosus are normally sold for US $\$ 10-15 / \mathrm{kg}$ at local farmers' markets, which is higher than the most other wild edible mushrooms, such as Boletus edulis and Cantharellus cibarius. Collection and trade of $P$. portentosus can bring good incomes to local farmers, and this is especially important for poor families in mountainous areas. Mr. Wang, for example, a young man of the minority Yi ethnic group, is a farmer living in Xinghuoshan village, Menghai county, Yunnan, who has been collecting and trading $P$. portentosus since his boyhood. He harvests the mushrooms during the mushroom season (June to September), and during this time can collect up to $10-20 \mathrm{~kg} /$ day. Harvesting $P$. portentosus can generate a good cash income of up to US $\$ 9,000 /$ year, or even more, for Mr. Wang. To Mr. Wang and his family, the income generated from the harvest of $P$. portentosus is indispensable, and has been used to build new houses, send children to school, visit doctors, purchase daily goods and set up his new business. Ms. Yang and her family live in Kelang village, Miyi county, Sichuan province $\left(22^{\circ} 50^{\prime} \mathrm{N}, 108^{\circ} 17^{\prime} \mathrm{E}\right)$, in the Jinsha River dry-hot valley region. Ms. Yang collects P. portentosus in the early mornings and takes them to a local farmers' market during the mushroom growth season (May to October). The money for construction of her new three-story building was gained in part from selling $P$. portentosus. In Happy town, Yun county, Yunnan, there is a loquat orchard of 7 ha $\left(23^{\circ} 53^{\prime} \mathrm{N}, 100^{\circ} 05^{\prime} \mathrm{E}\right)$, and has very high yield of $P$. portentosus. During the mushroom growth season, up to $100-150 \mathrm{~kg}$ of $P$. portentosus can be harvested per day, generating around US\$300-450/d. The production of $P$. portentosus from the orchard has generated an important side income for her business (up to US $\$ 15,000 /$ year). There is a $D$. regia plantation of 1.66 ha at a nursery in Manmeke village, Jinghong city, Yunnan, with a production of $P$. portentosus worth around US $\$ 30,000 /$ year. The cash generated from the mushroom harvest is enough to pay the wages of the 
nursery workers. At the 0.4 ha Dongfeng orchard of $C$. grandis in Jinghong City, Yunnan, the production of $P$. portentosus generates around US\$3,890/year. The above are a few examples of the harvest and trade of $P$. portentosus. There are more than 20 regions in Southern China producing $P$. portentosus, and each has more than one location (Fig. 4). Income generated from the harvest and trade of $P$. portentosus is important for the farmers in these regions.

\section{Cultivation}

Due to a widespread decline in production of $P$. portentosus, research into different cultivation methods has been undertaken by the authors' team at the Yunnan Institute for Tropical Crop Research since 2003. Cultivation technologies have been developed for P. portentosus in mushroom houses (Fig. 8) and using field inoculation (Fig. 13) [9-11]. To date, this is the only species in the Boletales which can be successfully cultivated worldwide. Field inoculation has been used to inoculate fruit trees, such as $C$. grandis, and double crops (fruit and mushrooms) have consequently been produced. The technology is simple, low cost and with low-carbon investment, suitable for promotion in rural areas.

\section{Discussion}

Visitors travelling through Yunnan during the mushroom growth season (June to October) are often deeply impressed by the wide variety and quantities of wild edible mushrooms at markets, and world's richest diversity of wild edible mushrooms, with over 600 edible wild species are recorded [29], also because of the diverse ethnic knowledge in this province. Yunnan has 26 nationalities and 25 of these are ethnic minorities. Most of the minorities are people living in mountainous regions who have a long history of using wild mushrooms. $P$. portentosus is a precious natural delicacy in the warm subtropical and tropical regions of China, in particular for the Dai people. $P$. portentosus is a species in the genus of
Phlebopus, Boletinellaceae. This family has another genus of Boletinellus, which has a species of $B$. merulioides. B. merulioides has symbiotic association with insect of aphids and also produces gall-like scleroderma, which contains one aphid inside [30]. $P$. portentosus associates symbiotically with mealy bugs through forming the insect-fungus gall. These ecological and biological features of these two genera make the family of Boletinellaceae unique and distinguished from other families in Boletales. Recent molecular research on Boletales revealed that saprophytic biotrophy could be the original biotrophic status during the biotrophic evolution of fungi in Boletales. And the symbiotic status could be evolved from the saprophytic biotrophy [31]. The $P$. portentosus can be saprophytic, but the main biotrophic status is to form a tripartite association with root mealy bugs and plants. Study on this tripartite association has great significance for further understanding the evolution of Boletales fungi. The secrets hidden in the tripartite association have been partially revealed during 10 years' study on $P$. portentosus. However, more details of the secrets need further research to be revealed. For example, recent examination of the insect-fungus galls often discovered that ants were involved into the process of formation of the galls, as the mutualism between ants and honey dew producers was discovered by Way et al. in 1963 [31].

\section{Conclusions}

The favorite edible mushroom, the black bolete of Southern China, has been identified as $P$. portentosus, although molecular evidence from the type collections is not available. It has been found in Northern Thailand and Sri Lanka, and is distinct from the Phlebopus species found in New Zealand, Australia and other continents. Its ecological and biotrophic status is complicated, involving symbiosis with both soil mealy bugs and plants, but it can also live as a saprobe. This tripartite association involved with three 
biological kingdoms: fungus, plant and animal.

$P$. portentosus is widely found in the tropical and subtropical forest regions of Southern China, particularly in artificial ecosystems. Harvest and trade of $P$. portentosus is an important means of livelihood for local people, especially for poor minorities. The cash income generated from its harvest can be several times that gained from growing rice or maize.

$P$. portentosus has been successfully cultivated both in mushroom houses and by the mycelial inoculation of fruit trees or other plants in the field.

\section{Acknowledgments}

Sincere thanks to Toni Atkinson for her editing of the paper. This study was supported by the Key Project of Applied Basic Research of Yunnan Province (No. 2017FA017), the Funds of Sci-Tech Innovation System Construction for Tropical Crops of Yunnan Province (No. RF2017-10), the Special Fund of Technological Development for Yunnan Institutions (No. 2015DC014), the National Natural Science Foundation of China (No. 31560008) and "Western Light"-Personnel Training Project of the Chinese Academy of Sciences (No. 326). This study was also supported by the New Zealand Institute for Plant \& Food Research Ltd.

\section{References}

[1] Sanmee, R., Dell, B., Lumyong, P., Izumori, K., and Lumyong, S. 2003. "Nutritive Value of Popular Wild Edible Mushrooms from Northern Thailand." Food Chemistry 82: 527-32.

[2] Zhang, C. X., Ji, K. P., He, M. X., Cao, Y., Liu, J., and Wang, W. B. 2010. "Analysis on Nutrient Components of Phlebopus portentosus Fruit Bodies.” Journal of Yunnan University 32: 702-4.

[3] Yang, Z. L., and Zang, M. 2003. "Tropical Affinities of Higher Fungi in Southern China." Acta Botanica Yunnanica 25 (2): 129-44.

[4] Zhang, C. X., He, M. X., Cao, Y., Liu, J., Gao, F., Wang, W. B., Ji, K. P., Shao, S. C., and Wang, Y. 2015. "Fungus-Insect Gall of Phlebopus portentosus." Mycologia 107 (1): 12-20.

[5] Berkeley, M. J. 1845. "Decades of Fungi. Dec. III-VII. Australian Fungi." London Journal of Botany 4: 42-72.
[6] Berkeley, M. J., and Broome, C. E. 1873. "Enumeration of the Fungi of Ceylon. Part II., Containing the Remainder of the Hymenomycetes, with the Remaining Established Tribes of Fungi." Journal of the Linnean Society of London, Botany 14 (73): 29-64.

[7] Binder, M., and Bresinsky, A. 2002. "Derivation of a Polymorphic Lineage of Gastromycetes from Boletoid Ancestors." Mycologia 94: 85-98. doi: 10.2307/3761848.

[8] Kirk, P. M., Cannon, P. F., David, J. C., and Stalpers, J. A. 2008. Dictionary of the Fungi. 10th ed.. Wallingford: CABI Europe.

[9] Zhang, C. X., He, M. X., Liu, J., Cao, Y., Wang, W. B., and Wang, Y. 2014. "Nutritive Components Comparison of Cultivated, Semi-cultivated and Wild Phlebopus portentosus Fruit Bodies." Southwest China Journal of Agricultural Sciences 27 (6): 2497-500.

[10] Ji, K. P., He, M. X., Zhang, C. X., Liu, J., Wang, W. B., and Hou, J. Y. 2009. "Semi-artificial Simulate Cultivation of Phlebopus portentosus and the Durability of Hyphae on Host Roots.” Microbiology 36 (3): 377-82.

[11] Ji, K. P., Cao, Y., Zhang, C. X., He, M. X., Liu, J., Wang, W. B., and Wang, Y. 2011. "Cultivation of Phlebopus portentosus in Southern China.” Mycological Progress 10: 293-300. doi:10.1007/s 11557-010-0700-7.

[12] Ji, K. P., Zhang, C. X., Zeng, Y., Liu, C. F., He, M. X., and Wang, W. B. 2007. "Artificial Fungal Colony and Its Fruiting of Phlebopus portentosus (Boletaceae) in Pot." Acta Botanica Yunnanica 29 (5): 554-8.

[13] Sanmee, R., Lumyong, P., Dell, B., and Lumyong, S. 2010. "In Vitro Cultivation and Fruit Body Formation of the Black Bolete, Phlebopus portentosus, a Popular Edible Ectomycorrhizal Fungus in Thailand." Mycoscience 51: 15-22. doi:10.1007/s10267-009-0010-6.

[14] Kumla, J., Bussaban, B., Suwannarach, N., Lumyong, S., and Danell, E. 2012. "Basidiome Formation of an Edible Wild, Putatively Ectomycorrhizal Fungus, Phlebopus portentosus without Host Plant." Mycologia 104: 597-603. doi:10.3852/11-074.

[15] Zang, M. 2006. Flora Fungorum Sinicorum: Boletaceae (I). Vol. 22. Beijing: Science Press, 73-4.

[16] Lei, Q. Y., Zhou, J. J., and Wang, Q. B. 2009. "Notes on Three Bolete Species from China." Mycosystema 28 (1): 56-9.

[17] Mortimer, P. E., Karunarathna, S. C., Li, Q. H., Gui, H., Yang, X. Q., Yang, X. F., He, J., Ye, L., Guo, J. Y., Li, H. L., Sysouphanthong, P., Zhou, D. Q., Xu, J. C., and Hyde, K. D. 2012. "Prized Edible Asian Mushrooms: Ecology, Conservation and Sustainability." Fungal Diversity 56 (1): 31-47. doi:10.1007/s13225-012-0196-3.

[18] Zhang, C. X., He, M. X., Cao, Y., Liu, J., Gao, F., Wang, W. B., Ji, K. P., Shao, S. C., and Wang, Y. 2015. "Preliminary Studies on Trophic Relationships of 
Phlebopus portentosus, Soil Mealy Bug and Plant." Edible and Medicinal Mushrooms 23 (6): 359-63.

[19] Watling, R. 2001. "The Relationships and Possible Distributional Patterns of Boletes in South-East Asia." Mycological Research 105: 1440-8. doi:10.1017/s0953756201004877.

[20] Ji, K. P., Zeng, Y., Liu, C. F., Li, J. Z., and He, M. X. 2006. "Preliminary Study on Cultivation of Boletus brunneissimus Chiu on Modeling." Journal of Yunnan Agricultural University 21 (3): 399-405.

[21] Heinemann, P., and Rammeloo, J. 1982. "Observations on the Genus Phlebopus (Boletineae).” Mycotaxon 15 (1): 384-404.

[22] Pegler, D. N. 1986. "Agaric Flora of Sri Lanka." Kew Bulletin Additional Series 12: 1-519.

[23] Bandala, V. M., Montoya, L., and Jarvio, D. 2004. "Two Interesting Records of Boletes Found in Coffee Plantations in Eastern Mexico.” Persoonia 18: 365-80.

[24] Segedin, B. P. 1987. "An Annotated Checklist of Agarics and Boleti Recorded from New Zealand." New Zealand Journal of Botany 25: 185-215.

[25] Neves, M. A., and Capelari, M. 2007. "A Preliminary Checklist of Boletales from Brazil and Notes on Boletales Specimens at the Instituto de Botânica (SP) Herbarium, São Paulo, SP, Brazil." Sitientibus Rev. Univ. Estadual Feira Santana 7: 163-9.
[26] Pham, N. D. H., Takahashi, H., Fukiharu, T., Shimizu, K., Le, B. D., and Suzuki, A. 2012. "Phlebopus spongiosus sp. Nov. (Boletales, Boletinellaceae) with a Sponge-Like Tissue." Mycotaxon 119: 27-34. doi:10.5248/119.27.

[27] Zhang, C. X., He, M. X., Ji, K. P., Cao, Y., Liu, J., and Wang, W. B. 2012. "Studies on Ecological Characteristics of Phlebopus portentosus." Southwest China Journal of Agricultural Sciences 25 (2): 614-9.

[28] Zhang, C. X., He, M. X., Cao, Y., Liu, J., Gao, F., Wang, W. B., Ji, K. P., Shao, S. C., and Wang, Y. 2016. "Is Phlebopus portentosus an Ectomycorrhizal Mushroom?-On the Mycorrhizal Symbiosis of $P$. portentosus with Pine and Oak.” Acta Edulis Fungi 23 (1): $37-41$.

[29] Wang, L., and Yang, Z. L. 2006. "Wild Edible Fungi of the Hengduan Mountains, Southwestern China." In Proceedings of the Sino-German Symposium Sustainable Harvest of Non-timber Forest Products in China, 58-65.

[30] Way, M. J. 1963. "Mutualism between Ants and Honeydew Producing Homoptera." Annu. Rev. Entomol. 8: 307-44.

[31] Wilson, A. W., Binder, M., and Hibbett, D. S. 2012. "Diversity and Evolution of Ectomycorrhizal Host Associations in the Sclerodermatineae (Boletales, Basidiomycota)." New Phytologist 194 (4): 1079-95. 